\title{
Curative treatment of atrial fibrillation with intraoperative radiofrequency ablation: Short-term and midterm results
}

Friedrich W. Mohr, MD, PhD

Alexander M. Fabricius, $M^{a}$

Volkmar Falk, MD, $\mathrm{PhD}^{\mathrm{a}}$

Rüdiger Autschbach, MD, PhD

Nicolas Doll, MD

Ulrich von Oppell, MD, $\mathrm{PhD}^{\mathrm{a}}$

Anno Diegeler, MD, $\mathrm{PhD}^{\mathrm{a}}$

Hans Kottkamp, MD, $\mathrm{PhD}^{\mathrm{b}}$

Gerd Hindricks, MD, PhD ${ }^{b}$
From the Divisions of Cardiac Surgery and Cardiology, ${ }^{\mathrm{b}}$ Herzzentrum, University of Leipzig, Leipzig, Germany.

Read at the Eighty-first Annual Meeting of The American Association for Thoracic Surgery, San Diego, Calif, May 6-9, 2001.

Received for publication May 15, 2001; revisions requested June 25, 2001; revisions received Aug 2, 2001; accepted for publication Aug 8, 2001.

Address for reprints: Friedrich W. Mohr, $\mathrm{MD}, \mathrm{PhD}$, Abteilung für Herzchirurgie, Herzzentrum Leipzig, Russenstrasse 19, D-04289 Leipzig, Germany (E-mail: mohrf@medizin.uni-leipzig.de).

J Thorac Cardiovasc Surg 2002;123:919-27

Copyright () 2002 by The American Association for Thoracic Surgery

0022-5223/2002 $\$ 35.00+0 \quad \mathbf{1 2 / 6 / 1 2 0 7 3 0}$

doi: $10.1067 / \mathrm{mtc} .2002 .120730$
Objective: This report describes the early and midterm results after intraoperative radiofrequency ablation of atrial fibrillation for patients with isolated chronic atrial fibrillation or atrial fibrillation in combination with additional valvular and nonvalvular cardiac diseases.

Methods: From August 1998 to March 2001, a total of 234 patients with chronic atrial fibrillation underwent isolated intraoperative radiofrequency ablation alone $(\mathrm{n}=74,31.6 \%)$ or in combination with other cardiac procedures, such as mitral valve reconstruction $(\mathrm{n}=57,24.4 \%)$, mitral valve replacement $(\mathrm{n}=38,16.2 \%)$, aortic valve replacement $(\mathrm{n}=11,5.1 \%)$, coronary artery bypass grafting $(\mathrm{n}=8$, $5.0 \%)$, or a combination of the last with other cardiac procedures $(n=46,19.7 \%)$. In all cases anatomic reentrant circuits confined within the left atrium were eliminated by placing contiguous lesion lines involving the mitral anulus and the orifices of the pulmonary veins through the use of radiofrequency energy application (exposure time, 20 seconds). A median sternotomy was used in 101 cases (43.2\%), and video assistance through a right lateral minithoracotomy was used in 133 cases $(56.8 \%)$.

Results: A total of 188 patients $(83.9 \%)$ were discharged in sinus rhythm, 17 patients $(7.6 \%)$ had atrial fibrillation, and 19 patients $(8.5 \%)$ had atypical flutter. Pacemakers were implanted in 23 patients $(9.8 \%)$. There were 10 in-hospital deaths $(4.2 \%)$, and 30 -day mortality was 5 patients $(2.1 \%)$. In 3 cases $(1.3 \%)$ an atrioesophageal fistula developed, necessitating surgical repair. Six months' follow-up was complete for $122(61.0 \%)$ of 200 patients, with 99 patients still in stable sinus rhythm $(81.1 \%, 95 \%$ confidence interval $73.1 \%-89.9 \%)$. Twelve months' follow-up was complete for $80(90.9 \%)$ of 88 patients, with 58 patients still in sinus rhythm (72.5\%, 95\% confidence interval 61.3\%-83.2\%).

Conclusions: Intraoperative radiofrequency ablation is a curative procedure for chronic atrial fibrillation. It is technically less challenging than the maze procedure and can be applied through a minimally invasive approach. Protection of the esophagus seems mandatory to avoid the deleterious complication of a left atrioesophageal fistula, such as was observed in 3 cases. 


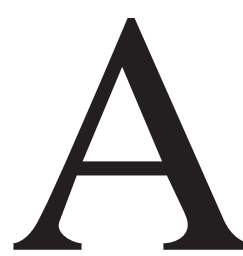

trial fibrillation (AF) is the most common sustained arrhythmia and is associated with substantial morbidity and mortality. ${ }^{1,2}$ A number of interventional concepts that are based on eliminating the initiating trigger or modifying the maintaining substrate have evolved within the past 2 decades. Catheterbased interventions for ventricular rate control, such as atrioventricular junction ablation or atrioventricular nodal modification, have the disadvantage of persistence of $\mathrm{AF}^{3}$ Surgical techniques such as the corridor operation ${ }^{4}$ or left atrial isolation ${ }^{5}$ effectively restore sinus rhythm but not biatrial transport function. The maze procedure 6,7 and the so-called radial approach, ${ }^{8,9}$ although highly effective, are technically demanding and time consuming, and they therefore have not found widespread application outside a few centers of excellence.

Percutaneous radiofrequency ablation to induce right atrial lesions for the treatment of paroxysmal AF has shown to be feasible. ${ }^{10}$ However, the reported success rates were only $13 \%$ if only the right atrium was ablated and $44 \%$ to $47 \%$ if additional lines were made in the left atrium, potentially replicating the maze concept. ${ }^{11,12}$ For the treatment of idiopathic AF, catheter-based radiofrequency ablation has shown poor results. One hundred percent of all patients who underwent ablation confined to the left atrium had recurrence of $\mathrm{AF}^{13}$ as a result of technical difficulties that prevented the creation of the intended left atrial line pattern. In right atrial ablation, recurrence was $94 \%$ despite creation of complete line patterns in the right atrium in half of the treated patients. ${ }^{13}$ In addition to excessive procedural times for percutaneous radiofrequency ablation of 5 to 10 hours, ${ }^{12,13}$ there are several procedure-related complications such as cardiac tamponade, stroke, thromboembolism, and pulmonary vein stenosis. ${ }^{11-14}$

Recently, the concept of surgical elimination of anatomically determined left atrial "anchor" reentrant circuits by induction of contiguous left atrial lesion lines between the pulmonary veins and the mitral anulus with radiofrequency energy has been introduced. Under direct vision completeness of the lesion line has been verified, with short procedure times. ${ }^{15}$ In this article we describe our experience and early and midterm outcomes in 234 patients with chronic AF who underwent intraoperative radiofrequency ablation of AF, either isolated or in combination with other cardiac procedures.

\section{Patient Characteristics}

From August 1998 to March 2001, a total of 234 patients were treated with intraoperative radiofrequency ablation of AF at our institution. Primary indication for intraoperative radiofrequency ablation was chronic persistent AF or symp- tomatic chronic paroxysmal AF refractory to medical treatment. There were 143 men and 91 women, with a mean age of $62.8 \pm 11.0$ years. The average duration of AF was $7.8 \pm$ 5.2 years. Twenty-nine patients $(12.4 \%)$ had a reduced left ventricular ejection fraction of less than $35 \%$, and of these 4 patients underwent $(1.7 \%)$ reoperation. Mean left ventricular function was $53.7 \% \pm 13.9 \%$, and mean left atrial diameter was $58.0 \pm 11.5 \times 49.3 \pm 10.9 \mathrm{~mm}$. Associated morphologic cardiac disease included mitral stenosis $(\mathrm{n}=$ $52,22.2 \%)$, mitral valve regurgitation $(\mathrm{n}=94,40.2 \%)$, severe tricuspid regurgitation $(\mathrm{n}=18,7.7 \%)$, atrial septal defect $(\mathrm{n}=4,1.7 \%)$, coronary artery disease $(\mathrm{n}=34$, $14.5 \%)$, aortic valve stenosis $(n=31,13.2 \%)$, aortic valve insufficiency ( $\mathrm{n}=1,0.4 \%$ ), and dilated cardiomyopathy $(\mathrm{n}=8,3.4 \%)$. Sixteen patients $(6.8 \%)$ with AF already had permanent pacemaker implantation before intraoperative radiofrequency ablation because of symptomatic bradycardia $(n=6,2.6 \%)$ or total atrioventricular block $(n=10,4.3 \%)$ before the operation.

\section{Surgical Procedure}

Patients were operated on through a median sternotomy $(\mathrm{n}=101,43.2 \%)$ or through a minimally invasive surgical approach through a right lateral minithoracotomy $(\mathrm{n}=133$, $56.8 \%$ ). Categorizing all patients into groups determined by surgical procedure and approach, 3 groups were defined: intraoperative radiofrequency ablation as primary indication for operation and performed minimally invasively (group A, $\mathrm{n}=74$ patients), ablation and mitral valve surgery with minimally invasive technique or conventional technique (group $\mathrm{B}, \mathrm{n}=95$ ), and ablation combined with other cardiac procedures in a conventional technique (group $\mathrm{C}$, $\mathrm{n}=65$; Table 1).

In the sternotomy group standard aortic and right atrial cannulation was performed and antegrade crystalloid or cold blood cardioplegia was administered. After opening of the left atrium, intraoperative radiofrequency ablation of AF was performed as described here.

In the minimally invasive group a right lateral minithoracotomy $(4-6 \mathrm{~cm})$ in the fourth intercostal space was performed and bypass was established by femorofemoral cannulation. For arterial cannulation a $16 \mathrm{~F}$ to $20 \mathrm{~F}$ arterial cannula was used (Baxter Healthcare Corporation, Edwards Division, Irvine, Calif). Venous drainage was achieved with a 22F femoral cannula (Heartport, Inc, Redwood City, Calif) and a $16 \mathrm{~F}$ arterial cannula inserted in the right internal jugular vein (Baxter Edwards) with enhanced venous drainage with vacuum assistance. Direct aortic clamping was performed with a transthoracic clamp (Chitwood clamp; Scanlan International, St Paul, Minn) inserted percutaneously in the second intercostal space. Antegrade cold crystalloid cardioplegia or cold blood cardioplegia was ap- 
plied for myocardial protection by puncture of the ascending aorta. After exposure of the left atrium, it was incised parallel to the interatrial groove anterior to the right pulmonary veins, thus allowing direct access to the mitral anulus as well as to the orifices of the pulmonary veins. No further atriotomy was performed, and the right atrium was not opened except in case of concomitant tricuspid valve repair. The left atrial appendage was not excised or ligated. Continuous carbon dioxide insufflation was used to evacuate air from the operative field.

\section{Radiofrequency Ablation (Figure 1)}

For intraoperative radiofrequency ablation a $10-\mathrm{mm}$ T-shaped ablation probe (Osypka GmbH, GrenzachWyhlen, Germany) was used. Alternating current was delivered by a generator $(350 \mathrm{kHz}$, modified HAT 200S; Osypka) with maximum energy levels of $50 \mathrm{~W}$ in a unipolar mode between the tip electrode and a $10 \times 16-\mathrm{cm}$ external backplate electrode to achieve a temperature of $60^{\circ} \mathrm{C}$ at its tip. Power, impedance, and tip temperature were monitored continuously throughout the procedure. With assurance of catheter stability, well-visualized endocardial lesion lines at the previously selected catheter tip temperature were placed, and the ablation probe was stepwise withdrawn after 20 seconds. A contiguous lesion line extending from the inferior aspect of the mitral anulus to the left lower pulmonary vein was performed. Through a second line the left lower and upper pulmonary vein orifices were connected. Through a third line the left and right upper pulmonary veins were connected. Finally, the right upper and left lower pulmonary vein orifices were connected. An additional line at the left atrial roof was at last extended to the surgical incision. The number of applications performed depended on the size of the left atrium. The ablation procedure was always performed before any other surgical procedures were performed.

\section{Postoperative Management and Follow-Up}

After the operation all patients were monitored daily with 12-lead electrocardiographic recordings for the first 5 postoperative days. In addition, two 24-hour electrocardiographic recordings were performed for every patient. In cases of postoperative AF that occurred within 10 days after the operation, electric cardioversion was performed either alone or in combination with the administration of amiodarone, flecainide, or sotalol. Patients in stable sinus rhythm (as defined by the presence of a $\mathrm{P}$ wave) without additional antiarrhythmic therapy received anticoagulation for 3 months; all patients who were receiving additional antiarrhythmic drugs received anticoagulation for 6 months. Patients were evaluated on discharge and 6 months thereafter by a 12-lead electrocardiography and 24-hour Holter monitoring. Follow-up was considered complete for patients

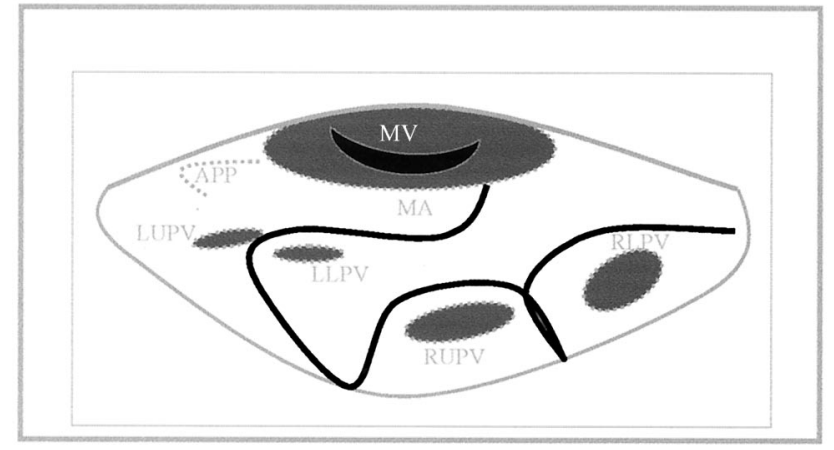

Figure 1. Intraoperative radiofrequency ablation of AF: lesion concept. $M V$, mitral valve; $M A$, mitral anulus; $A P P$, appendage; $L U P V$, left upper pulmonary vein; $L L P V$, left lower pulmonary vein; $R U P V$, right upper pulmonary vein; $R L P V$, right lower pulmonary vein.

seen at the 6- and 12-month follow-up examinations. On the basis of these data, a 95\% confidence interval (CI) was calculated.

\section{Statistical Analysis}

Continuous variables are expressed as mean \pm SD. A $95 \%$ CI for the probability of success was calculated by the Clopper-Pearson method for dichotomous data, which takes into account the number of examinations, thus yielding probability intervals for sinus rhythm at discharge and at 6 and 12 months' follow-up. Statistical calculations were performed with StatXact (release 4.0; Cytel Software Corporation, Cambridge, Mass).

\section{Results}

Mean operating time was $167.1 \pm 53.3$ minutes, mean duration of cardiopulmonary bypass was $114.1 \pm 38.1$ minutes, mean crossclamp time was $69.0 \pm 28.4$ minutes, and mean procedural time for ablation was $17.2 \pm 8.1$ minutes. On admission to the intensive care unit, patients were either in spontaneous sinus rhythm (83.3\%) or electrically paced in atrioventricular universal (DDD) or atrial inhibited (AAI) mode (16.6\%).

\section{Early Recurrence of Atrial Fibrillation and Perioperative Arrhythmias}

Perioperative atrial arrhythmias were observed in 143 patients $(61.1 \%)$ as supraventricular tachyarrhythmia $(\mathrm{n}=71$, $30.3 \%)$, atypical flutter ( $\mathrm{n}=112,47.9 \%)$, or both. A total of 133 patients were treated successfully with one or more cardioversions alone $(56.8 \%)$ or in combination with amiodarone ( $\mathrm{n}=92,39.3 \%)$, flecainide $(\mathrm{n}=30,12.8 \%)$, or sotalol $(\mathrm{n}=21,8.9 \%)$. Ninety $(38.5 \%)$ patients had to be 
TABLE 1. Patient characteristics

\begin{tabular}{lcccc}
\hline & Group A (n= 74) & Group B (n= 95) & Group C (n= 65) & Total (n= 234) \\
\hline Age (y, mean \pm SD) & $53.10 \pm 9.8$ & $66.20 \pm 11.80$ & $69.10 \pm 6.2$ & $62.86 \pm 11.00$ \\
Sex ratio (male/female) & $57 / 17$ & $43 / 52$ & $43 / 22$ & $143 / 91$ \\
AF duration (y, mean \pm SD) & $7.5 \pm 6.9$ & $6.6 \pm 6.1$ & $8.2 \pm 5.2$ & $7.8 \pm 5.2$ \\
Left ventricular ejection & $62.3 \pm 9.5$ & $51.9 \pm 13.6$ & $50.73 \pm 13.7$ & $53.73 \pm 13.92$ \\
$\quad$ & & & \\
fraction (\%, mean \pm SD) & $50.2 \pm 7.6 \times$ & $65.25 \pm 10.5 \times$ & $59.6 \pm 11.8 \times$ & $58.03 \pm 11.53 \times$ \\
$\quad$ mean \pm SD) & $40.6 \pm 7.6$ & $56.0 \pm 10.1$ & $49.7 \pm 10.3$ & $49.32 \pm 10.95$ \\
\hline
\end{tabular}

Group $A$, Intraoperative radiofrequency ablation of AF as primary indication with surgery through minimally invasive technique; group $B$, intraoperative radiofrequency ablation of $\mathrm{AF}$ and mitral valve surgery; group $C$, intraoperative radiofrequency ablation of $\mathrm{AF}$ combined with other surgical procedures.

monitored for more than 3 days in the intermediate care unit because of unstable cardiac rhythms.

\section{Discharge}

Of the patients discharged $(\mathrm{n}=224)$, sinus rhythm was established in 188 patients (83.9\%); 19 patients $(8.5 \%)$ were discharged with atypical flutter, and 17 patients $(7.6 \%)$ were discharged with persisting AF.

In a comparison by groups, restoration of sinus rhythm was successful in $91.9 \%$ of cases in group A $(n=68)$, $76.8 \%$ of cases in group B ( $\mathrm{n}=73)$, and $72.3 \%$ of cases in group C $(\mathrm{n}=47)$. In group A $1.4 \%$ of the patients $(\mathrm{n}=$ $1 / 74$ ) were discharged with atypical flutter, as compared with $5.3 \%$ in group $B(n=5 / 95)$ and $6.2 \%$ in group $C(n=$ $4 / 65$ ). Atypical flutter was observed in $5.4 \%$ of patients in group A $(\mathrm{n}=4 / 74), 12.6 \%$ of patients in group B $(\mathrm{n}=$ $12 / 95)$, and $4.6 \%$ of patients in group $C(n=3 / 65)$. In 23 cases $(9.8 \%)$ a permanent pacemaker implantation was needed after the operation because of sinus bradycardia, with or without sinus arrest or atrioventricular dissociation.

\section{Six Months' and 12 Months' Follow-up (Table 2)}

After 6 months 97.4\% (37/38) of group A, 77.8\% (42/54) of group B, and $66.7 \%$ (20/30) of group C were in sinus rhythm, respectively. Sinus rhythm with intermittent AF or atypical flutter was observed in $2.6 \%(1 / 38)$ in group A, $11.1 \%(6 / 54)$ in group B, and $3.3 \%(1 / 30)$ in group C. Atypical flutter was seen in 5.6\% (3/54) in group B and $3.3 \%(1 / 30)$ in group C. Six months' follow-up was complete in 122 of 200 patients $(61.0 \%)$ with 99 patients still in stable sinus rhythm (81.1\% [95\%, CI: 73.1-89.9]). In 2 patients an isthmus ablation was performed due to atrial flutter (1.8\%); 3 patients required an additional 2-chamber pacemaker implantation (2.8\%). One patient required reoperation after initial mitral valve reconstruction due to recurrent mitral valve regurgitation. Two patients $(0.8 \%)$ had a cerebral stroke during the follow-up period.

After 12 months 93.8\% (15/16) of group A, 70.0\% (30/43) of group B, and $61.9 \%$ (13/21) of group C were in sinus rhythm, respectively.
Sinus rhythm with intermittent AF or atypical flutter was observed in 6.3\% (1/16) in group A, 2.3\% (1/43) in group B, and $4.8 \%(1 / 21)$ in group C. Atypical flutter was observed in $7.0 \%(3 / 43)$ in group B and $4.8 \%(1 / 21)$ in group C. Twelve months' follow-up was complete in 80 of 88 patients (90.9\%) with 58 patients still in sinus rhythm (72.5\% [95\% CI: $61.3 \%-83.2 \%]$ ). One patient required an additional 2-chamber pacemaker implantation $(0.4 \%)$ and 1 patient $(0.4 \%)$ had a cerebral stroke during the follow-up period. Three patients had died after 12 months, 2 of unknown cause and 1 of a cerebral stroke.

\section{Complications, Morbidity, and Mortality}

Two patients $(0.8 \%)$ required conversion from minithoracotomy to median sternotomy. Reexploration for bleeding was required in 18 patients $(6.8 \%)$, and 6 patients required postoperative circulatory support such as intra-aortic balloon pumping ( $\mathrm{n}=5,2.1 \%)$ or extracorporeal membrane oxygenation $(\mathrm{n}=2,0.8 \%)$. Two patients $(0.8 \%)$ required reoperation within 5 days after the initial operation: 1 patient had mitral valve regurgitation after initial reconstruction and 1 patient had a prosthesis infection. Two patients $(0.8 \%)$ had sternal infections, 1 patient $(0.4 \%)$ showed perioperative ischemia caused by stenosis of the circumflex artery, which was successfully treated by angioplasty and stent implantation, and 3 patients $(1.3 \%)$ had cerebral strokes after the operation. Three patients $(1.2 \%)$ had atrioesophageal perforations, and 2 of them had successful reoperations. One patient $(0.4 \%)$ died of severe cerebral infarction, and 1 patient $(0.4 \%)$ had an inguinal infection after femorofemoral cannulation.

Mortality was 15 patients (6.4\%); 10 patients (4.2\%) died during postoperative hospitalization, with a mean hospitalization time of 33.8 days (range 10-96 days). Two patients $(0.8 \%)$ died of adult respiratory distress syndrome, 1 patient died $(0.4 \%)$ of pulmonary embolism, 3 patients $(1.3 \%)$ died of sepsis, 2 patients $(0.8 \%)$ died of low cardiac output, 1 patient $(0.4 \%)$ died of stroke, and 1 patient $(0.4 \%)$ died of unknown causes. 
TABLE 2. Discharge, 6 months, and 12 months of follow-up

\begin{tabular}{|c|c|c|c|c|}
\hline \multicolumn{5}{|c|}{ Group A: IRAAF as primary indication with surgery via minimally invasive technique } \\
\hline Discharge & SR $91.9 \%(68 / 74)$ & SR/AFL & - & AFL $1.4 \%(1 / 74)$ \\
\hline Six months & SR $97.4 \%(37 / 38)$ & SR/AFL & $2.6 \%(1 / 38)$ & $\mathrm{AFL}-$ \\
\hline Twelve months & SR $93.8 \%(15 / 16)$ & SR/AFL & $6.3 \%(1 / 16)$ & AFL - \\
\hline \multicolumn{5}{|c|}{ Group B: IRAAF and mitral valve surgery in minimally invasive technique } \\
\hline Discharge & SR $76.8 \%(73 / 95)$ & AR/AFL & - & AFL $12.6 \%(12 / 95)$ \\
\hline Six months & SR $77.8 \%(42 / 54)$ & $\mathrm{SR} / \mathrm{AF}$ & $11.1 \%(6 / 54)$ & AFL $5.6 \%(3 / 54)$ \\
\hline Twelve months & SR $69.2 \%(30 / 43)$ & $\mathrm{SR} / \mathrm{AF}$ & $2.3 \%(1 / 43)$ & AFL 7.0\% (3/43) \\
\hline \multicolumn{5}{|c|}{ Group C: IRAAF combined with other surgical procedures } \\
\hline Discharge & SR $72.3 \%(47 / 65)$ & & & AFL $4.6 \%(3 / 65)$ \\
\hline Six months & SR $66.7 \%(20 / 30)$ & SR/AFL & $3.3 \%(1 / 30)$ & AFL $3.3 \%(1 / 30)$ \\
\hline Twelve months & SR $61.9 \%(13 / 21)$ & SR/AFL & $4.8 \%(1 / 21)$ & AFL $4.8 \%(1 / 21)$ \\
\hline \multicolumn{5}{|l|}{ Follow-up: } \\
\hline Six months & \multirow{2}{*}{\multicolumn{2}{|c|}{$\begin{array}{l}\text { SR } 81.1 \%(99 / 122) \\
\text { SR } 72.5 \%(58 / 80)\end{array}$}} & \multirow{2}{*}{\multicolumn{2}{|c|}{$\begin{array}{l}{[95 \% \text { Cl: } 73.1 \%-89.9 \%]} \\
{[95 \% \text { Cl: } 61.3 \%-83.2 \%]}\end{array}$}} \\
\hline Twelve months & & & & \\
\hline
\end{tabular}

$S R$, Sinus rhythm; $S R / A F L$, SR with intermittent atrial fibrillation or atypical flutter; $A F L$, atypical flutter; $L A$, left atrial diameter.

All deaths but 1 (of cerebral air embolism after atrioesophageal infarction) were related to the high-risk profile of the underlying cardiac disease and not to the intraoperative radiofrequency ablation procedure. There were no deaths among the patients treated for isolated chronic or paroxysmal AF. Atrioesophageal perforation was the only procedure-related complication, and in 1 case $(0.4 \%)$ it was lethal.

\section{Discussion}

The maze procedure was introduced by Cox and associates ${ }^{16}$ in 1991 as a curative therapy for patients with chronic AF. Depending on inclusion criteria, restoration of sinus rhythm is possible for $65 \%$ to $93 \%$ of the patients. ${ }^{6,17-19}$ Reported mortality for combined operations and the need for postoperative pacemaker implantation are in the range of $0 \%$ to $5 \%$ and $2 \%$ to $14 \%$, respectively. ${ }^{19}$ Several attempts have been made to develop simpler but equally effective surgical treatment strategies, but so far none has exceeded the good results of the original maze III procedure. ${ }^{5,8,20}$

In 1997 Patwardhan and colleagues ${ }^{21}$ reported the use of intraoperative radiofrequency coagulation to induce contiguous lesion lines to replace the right and left atrial incisions of the maze III procedure. A combined approach with surgical incisions and radiofrequency-induced linear lesions was introduced by Sie and coworkers, ${ }^{22}$ reducing the operating time for the maze procedure. Melo and associates ${ }^{23}$ used radiofrequency-induced contiguous left atrial lesion lines around the pulmonary veins for surgical pulmonary vein isolation and achieved restoration of sinus rhythm in $71 \%$ of their cases. A similar approach of surgical isolation of the pulmonary veins with cryoablation was recently reported by Sueda and colleagues. ${ }^{24}$ At a mean follow-up of
8 months, $83 \%$ of their patients $(n=12)$ were in sinus rhythm.

Whereas these strategies have aimed at isolating the focus for $\mathrm{AF}$, our strategy for intraoperative radiofrequency ablation of AF follows the concept of elimination of anatomically determined left atrial "anchor" reentrant circuits by induction of contiguous left atrial lesion lines between the pulmonary veins and the mitral anulus with radiofrequency energy. ${ }^{25,26}$ This concept is based on the hypothesis that anatomically defined left atrial reentrant circuits are crucial for the perpetuation of AF. These circuits anchor around the pulmonary vein orifices when functional reentrant circuits have been extinguished, thereby ensuring maintenance of $\mathrm{AF}$ and preventing its termination. ${ }^{27}$

An initial study $(\mathrm{n}=12)$ demonstrated that a restricted approach of elimination of anatomically defined anchor reentrant circuits within the left atrium prevented chronic $\mathrm{AF}$ in more than $80 \%$ of patients with mitral valve disease and chronic AF. ${ }^{27}$ Further modifications of the technique have allowed its routine application through a minimally invasive approach through a right anterolateral minithoracotomy, ${ }^{28}$ which is currently the access of choice for isolated mitral valve surgery at our institution..$^{29,30}$ The patients included in this study represent an unselected group of patients with a variety of cardiac diseases who underwent intraoperative radiofrequency ablation, either alone or in combination with additional cardiac procedures. Morbidity, mortality, freedom from AF at early and midterm follow-up, and the need for postoperative pacemaker implantation are comparable to the results of the maze III procedure. Whereas the maze III procedure is a relatively rare operation (76 patients in a 5-year period at one institution ${ }^{31}$ and 346 patients in a 12-year period at the leading center $^{32}$ ), the 
ease of application of intraoperative radiofrequency ablation allowed its use in 234 patients in a 2-year period, with about half of the patients operated on in a minimally invasive fashion. The avoidance of a sternotomy has largely increased patient acceptance of surgical treatment for isolated $\mathrm{AF}$ and is the major reason for increased patient referral for antiarrhythmic surgical treatment. Relative to the maze procedure, aortic crossclamp and cardiopulmonary bypass times are shorter, and postoperative diuretic treatment for atrial natriuretic peptide deficiency is not necessary. ${ }^{33}$ The limited left atrial approach will, of course, not eliminate atrial flutter originating from the right atrium, as the maze procedure does. As our data in group A clearly demonstrate, however, this approach is highly effective to treat standalone AF. Postoperative atrial flutter was therefore not encountered as recurrence of AF among our patients and was subsequently treated successfully by catheter techniques in some cases.

There are, however, new procedure-related complications that require careful application of this technique. In 3 cases we found atrioesophageal fistulas that were seen after an initial uncomplicated recovery at postoperative intervals of 3 and 6 days, with repetitive neurologic deficits caused by multiple air embolisms in 2 patients. Both of the latter patients underwent reoperation for repair of the esophagus and left atrium. In another case sudden onset of upper gastrointestinal tract bleeding necessitated gastroscopy. After insufflation of carbon dioxide, massive cerebral air embolism occurred, from which the patient died. All other deaths $(n=9)$ were not procedure related. Although the exact mechanism of esophageal injury after intraoperative radiofrequency ablation of AF and subsequent transesophageal echocardiographic studies is still speculative, the most likely cause of this detrimental sequel is a thermal injury during radiofrequency application, in combination with mechanical trauma induced by the echocardiographic probes. In all cases a transesophageal echocardiography probe was in place before and 3 to 6 days after the operation to study left atrial contractility, and this may have caused additional mechanical irritation. Since the first complication occurred, we no longer leave the probe in the esophagus during ablation and have switched to transthoracic echocardiography during the early postoperative period. In addition, an isolating scrub is placed into the sinus obliquus pericardii behind the left atrial wall to prevent the passage of electric and thermal energy through the esophagus. Esophageal perforations have been observed by others with different radiofrequency catheter devices and also in some cases after transesophageal echocardiographic studies alone. This complication needs further investigation.

Several studies with percutaneous radiofrequency catheter ablation within the right atrium showed an extremely limited efficacy, indicating that induction of right atrial lesions is not sufficient to cure AF. The lesion geometries that have been applied percutaneously so far seem to be empirically derived, and no successful lesion geometry concept for percutaneous application has been validated. Failure to induce continuous lesion lines necessary for proper isolation has led to the poor results reported for catheterbased left atrial ablation. In addition to a disappointing $100 \%$ recurrence rate, complications of catheter-based interventions included cerebral infarction, tamponade necessitating immediate pericardiocentesis, retroperitoneal hematoma, and pneumothorax, as well as pericardial effusions and pacemaker implantations. ${ }^{13}$

Because of the poor results of catheter-based interventions for the treatment of AF and in the light of the relatively small numbers of maze procedures that are performed, the concept of intraoperative radiofrequency ablation of AF seems to present a promising alternative. The necessity of avoiding procedure-related complications is obvious from the data presented here, but now that the mechanism of injury is known, means of prevention can be developed. The question whether different radiofrequency catheter probes or other energy sources, such as microwave and cryoablation, will demonstrate better surgical results requires future study.

\section{References}

1. Benjamin WJ, Wolf PA, D'Agostino RB, Silberschatz H, Kannel WB, Levy D. Impact of atrial fibrillation on the risk of death: the Framingham Heart Study. Circulation. 1998;98:946-52.

2. Obadia JF, El Farra M, Bastien OH, Liévre M, Martelloni Y, Chassignolle JF. Outcome of atrial fibrillation after mitral valve repair. J Thorac Cardiovasc Surg. 1997;114:179-85.

3. Lesh MD, Van Hare GF, Epstein LM, Fitzpatrick AP, Scheinman MM, Lee RJ, et al. Radiofrequency catheter ablation of atrial arrhythmias: results and mechanisms. Circulation. 1994;89:107489.

4. Velimirovic DB, Petrovic P, Djukic P, Vranes M, Pavlovic SU, Zivkovic M. Corridor procedure: surgical option for treatment of chronic atrial fibrillation in patients undergoing mitral valve replacement. Cardiovasc Surg. 1997;5:320-7.

5. Williams JM, Ungerleider RM, Lofland GK, Cox JL. Left atrial isolation: new technique for the treatment of supraventricular arrhythmias. J Thorac Cardiovasc Surg. 1980;80:373-80.

6. Cox JL, Schuessler RB, Lappas DG, Boineau JP. An 8-year clinical experience with surgery for atrial fibrillation. Ann Surg. 1996;224: 267-73.

7. Lee R, Nitta T, Schuessler RB, Johnson DC, Boineau JP, Cox JL. The closed heart MAZE: a nonbypass surgical technique. Ann Thorac Surg. 1999;67:1696-702.

8. Nitta T, Lee R, Schuessler RB, Boineau JP, Cox JL. Radial approach: a new concept in surgical treatment for atrial fibrillation. I. Concept, anatomic and physiologic bases and development of a procedure. Ann Thorac Surg. 1999;67:27-35.

9. Nitta T, Lee R, Watanabe H, Harris KM, Erikson JM, Schuessler RB, et al. Radial approach: a new concept in surgical treatment for atrial fibrillation. II. Electrophysiologic effects and atrial contribution to ventricular filling. Ann Thorac Surg. 1999;67:36-50.

10. Haissaguerre M, Gencel L, Fischer B, Le Metayer P, Poquet F, Marcus FI, et al. Successful catheter ablation of atrial fibrillation. J Cardiovasc Electrophysiol. 1994;5:1045-52.

11. Haissaguerre M, Jais P, Shah DC, Gencel L, Pradeau V, Garrigues $\mathrm{S}$, et al. Right and left atrial radiofrequency catheter therapy of 
paroxysmal atrial fibrillation. J Cardiovasc Electrophysiol. 1996; 7:1132-44.

12. Pappone C, Oreto G, Lamberti F, Vicedomini G, Loricchio ML, Shpun S, et al. Catheter ablation of paroxysmal atrial fibrillation using a 3D mapping system. Circulation. 1999;100:1203-8.

13. Ernst S, Schluter M, Ouyang F, Khanedani A, Cappato R, Hebe J, et al. Modification of the substrate for maintenance of idiopathic human atrial fibrillation: efficacy of radiofrequency ablation using nonfluoroscopic catheter guidance. Circulation. 1999;100:2085-92.

14. Robbins IM, Colvin EV, Doyle TP, Kemp WE, Loyd JE, McMahon WS, et al. Pulmonary vein stenosis after catheter ablation of atrial fibrillation. Circulation. 1998;98:1769-75.

15. Hindricks G, Mohr FW, Autschbach R, Kottkamp H. Antiarrhythmic surgery for treatment of atrial fibrillation: new concepts. Thorac Cardiovasc Surg. 1999;47 Suppl 3:365-9.

16. Cox JL, Schuessler RB, D'Agostino HJ, Stone CM, Chang BC, Cain $\mathrm{ME}$, et al. The surgical treatment of atrial fibrillation. III. Development of a definite surgical procedure. $J$ Thorac Cardiovasc Surg. 1991;101:569-83.

17. Kobayashi J, Kosakai Y, Nakano K, Sasako Y, Eishi K, Yamamoto F. Improved success rate of the maze procedure in mitral valve disease by new criteria for patients' selection. Eur J Cardiothorac Surg. 1998;13:247-52.

18. Isobe F, Kawashima Y, The outcome and indications of the Cox maze III procedure for chronic atrial fibrillation with mitral valve disease. J Thorac Cardiovasc Surg. 1998;116:220-7.

19. Arcidi JM, Millar RC. Evolution of the maze III procedure: are modifications necessary? Thorac Cardiovasc Surg. 1999;47 Suppl 3:362-4.

20. Sueda T, Nagata H, Orihashi K, Morita S, Okada K, Sueshiro M, et al. Efficacy of a simple left atrial procedure for chronic atrial fibrillation in mitral valve operations. Ann Thorac Surg. 1997;63: 1070-5.

21. Patwardhan AM, Dave HH, Tamhane AA, Pandit SP, Dalvi BV, Golam K, et al. Intraoperative radiofrequency microbipolar coagulation to replace incisions of maze III procedure for correcting atrial fibrillation in patients with rheumatic valvular disease. Eur J Cardiothorac Surg. 1997;12:627-33.

22. Sie HT, Beukema WP, Misier AR. Radiofrequency ablation of atrial fibrillation in patients undergoing valve surgery [abstract]. Circulation. 1997;96 Suppl:450.

23. Melo JQ, Neves J, Adragao P, Ribeiras R, Ferreira MM, Bruges L, et al. When and how to report results of surgery on atrial fibrillation. Eur J Cardiothorac Surg. 1997;12:739-45.

24. Sueda T, Imai K, Ishii O, Orihashi K, Watari M, Okada K. Efficacy of pulmonary vein isolation for the elimination of chronic atrial fibrillation in cardiac valvular surgery. Ann Thorac Surg. 2001;71: 1189-93.

25. Hindricks G, Kottkamp H, Hammel D, et al. Radiofrequency ablation of atrial fibrillation: early clinical experience with a catheterguided intraoperative approach [abstract]. Eur Heart J. 1997;18 Suppl:135.

26. Kottkamp H, Hindricks G, Hammel D, Autschbach R, Mergenthaler J, Borggrefe $\mathrm{M}$, et al. Intraoperative radiofrequency ablation of chronic atrial fibrillation: a left atrial curative approach by elimination of anatomic "anchor" reentrant circuits. J Cardiovasc Electrophysiol. 1999;10:772-80.

27. Kottkamp H, Hindricks G. Curative treatment of atrial fibrillation 2000: percutaneous catheter ablation techniques and intraoperative ablation with minimally invasive techniques. Herzschr Elektrophys. 2000;11 Suppl 2:II63-8

28. Kottkamp H, Mohr FW, Autschbach R, et al. Intraoperative cure from atrial fibrillation using radiofrequency energy: development of a safe and effective treatment strategy using minimal invasive techniques [abstract]. Pacing Clin Electrophysiol. 1999;22 Suppl: 848.

29. Mohr FW, Falk V, Diegeler A, Walther T, van Son JA, Autschbach R. Minimally invasive port-access mitral valve surgery. J Thorac Cardiovasc Surg. 1998;115:567-74.
30. Mohr FW, Onnasch JF, Falk V, Walther T, Diegeler A, Krakor R, et al. The evolution of minimally invasive valve surgery: 2 year experience. Eur J Cardiothorac Surg. 1999;15;233-8.

31. Millar RC, Arcidi JM, Alison PJ. The maze III procedure for atrial fibrillation: should the indications be expanded? Ann Thorac Surg. 2000;70:1580-6

32. Cox JL, Ad N, Palazzo T, Fitzpatrick S, Suyderhoud JP, DeGroot KW, et al. Current status of the Maze procedure for the treatment of atrial fibrillation. Semin Thorac Cardiovasc Surg. 2000;12:15-9.

33. Ad N, Pirovic EA, Kim YD, Suyderhoud JP, DeGroot KW, Lou HC, et al. Observations on the perioperative management of patients undergoing the Maze procedure. Semin Thorac Cardiovasc Surg. 2000; 12:63-7.

\section{Discussion}

Dr Michael Argenziano (New York, NY). In this article Mohr and associates reported their experience with a modified left atrial radiofrequency ablation procedure for patients with chronic $\mathrm{AF}$, performed either as a primary procedure or concomitant with coronary artery bypass grafting or valvular surgery. Despite the lack of randomization and absence of control groups, Mohr and associates are to be congratulated on this large clinical series, which demonstrates the feasibility and efficacy of surgical endocardial radiofrequency ablation of AF.

In addition, they are to be commended for advancing the development of this field in two important ways. First, they have demonstrated the feasibility of performing left atrial radiofrequency ablation as a primary procedure, with $\mathrm{AF}$ as the sole indication. It is interesting to note, in fact, that in this study ablations performed solely for AF actually resulted in higher midterm success rates than did ablations performed in combination with other cardiac operations. Second, by performing most of their procedures through small thoracotomy incisions, Mohr and associates have taken a critical step toward the ultimate goal of a totally minimally invasive surgical approach to the management of chronic AF.

I have several comments and questions, Dr Mohr. Your method of radiofrequency ablation is different from that used by our group and many others in that you do not circumferentially isolate the pulmonary veins and also do not electrically or mechanically exclude the left atrial appendage. As we have reported, we make a single encircling radiofrequency lesion around the pulmonary veins and a lesion to the mitral anulus but also make a lesion around the left atrial appendage and add a connecting line from this lesion to the pulmonary vein isolation line. We do this to exclude arrhythmogenic foci within the pulmonary veins and left atrial appendage, and also to prevent arrhythmias caused by reentrant conduction around the base of the appendage. Despite the differences in the techniques that we use, we have reported midterm success rates similar to those presented by you today for patients undergoing concomitant cardiac procedures such as mitral valve replacement. My first question is, how did you choose your lesion set, and which components of this set if any do you think are absolutely necessary for the reliable elimination of AF?

My second question relates to the handling of the left atrial appendage. In our experience, with careful inspection thrombus is often found within the appendage, even when it is not visualized by transesophageal echocardiography. For this reason we routinely ligate the appendage from within the atrium with a purse-string suture. Why have you chosen to leave the appendage open? And with regard to your patients who died of strokes, do you think it is 
possible that the source of embolization could have been the left atrial appendage?

My third question relates to two specific complications that occurred in your series: 3 atrioesophageal fistulas and 1 case of circumflex artery stenosis. Presumably, as you suggest, these injuries were induced by the radiofrequency probe. However, it seems unlikely to me that the application of radiofrequency energy controlled to a maximum temperature of $60^{\circ} \mathrm{C}$ to $65^{\circ} \mathrm{C}$ for only 20 seconds would cause this degree of damage, because most other authors have used higher target temperatures of $70^{\circ} \mathrm{C}$ to $80^{\circ} \mathrm{C}$ for much longer burn times, as long as 2 minutes, without significant injuries. Is it possible that the actual delivered temperature was higher than that recorded by the probe, as might be the case with continuous irrigation of the probe at the endocardial surface? Also, was too much pressure exerted on the probe in certain areas, perhaps because of inadequate exposure? To avoid these complications, we also routinely withdraw the transesophageal echocardiography probe at the time of radiofrequency delivery, and we also administer retrograde cardioplegia during radiofrequency application near the mitral anulus.

My next question is about your reference in your presentation to potential prophylactic use of this operation. You did not mention this in the article, but I presume that when you said prophylaxis, for instance, in patients having atrial septal defect closure, you meant that you actually applied this operation in patients who were not in AF at the time of surgery. If that is not what you meant, please clarify that.

Finally, although you mentioned that you performed echocardiographic evaluations to assess the effects of your operation on atrial transport function, you did not actually report those data. What were your findings with respect to atrial transport function in patients in whom you achieved electrocardiographic success?

I believe that this is a seminal contribution to this exciting field of surgical interest.

Dr Mohr. With respect to the prophylactic operations, these were patients who had AF but did not have severe symptoms. They were coming for an atrial septal defect closure or an autograft replacement and were in sinus rhythm, without AF at the time of the operation. So we considered this a prophylactic procedure. The same is true for the coronary artery bypass grafting operations.

The next question was about aortoesophageal fistulas. Actually, we are not the only ones who have observed aortoesophageal fistulas. They have also occurred with the other probe, the radiofrequency probe that your group is using. This has not been reported, but if you talk to some groups, you will discover that it has happened. I just wanted to draw attention to that. I truly believe that the radiofrequency itself may have some injury to the esophagus, with the mechanical push of the transesophageal echocardiographic probe, which was used after 1 week to evaluate left atrial contraction, perhaps finally causing the perforation. This is what I assume. I cannot tell you the reason.

With respect to the temperature, we have evaluated several radiofrequency probes, including the probe that you are using. The probe that you are using allows for a measurable temperature at the epicardium within 3 seconds up to $65^{\circ} \mathrm{C}$ and then it shuts off, whereas with the Boston Scientific probe it takes you up to 90 seconds to reach this epicardial temperature. This may well be why you do not have that effect on the esophagus. On the other hand, it does have an effect on continuous lines. If you look into the worldwide results with the other probe, they are worse than with our probe, because you are more likely to have a gap. At least we have found that in our laboratory.

The left atrial appendage is, as far as we can tell, a major part that helps in the contraction of the left atrium. If you cut it off, you will have a problem as with the Cox maze procedure in that you must continue diuretics all the time. You could sew the appendage closed, but in our study protocol we decided not to do so, so that we could measure the left atrial contractility also in the left atrial appendage.

To answer the question about the left atrial contractility, patients with normally sized left atria had normal left atrial contractility. If you remember Miller's scoring, it would be a score of 4 . Among patients who had dilated left atria that were downsized, the left atrial contractility was relatively low at the beginning but had recovered after 3 to 6 months.

Our lesion sets did not include the left atrial appendage. I think that if you go to the electrophysiology meeting, it is the clear opinion of the cardiologists that the left atrial appendage does not play a role. Most of them localize the multifocal lesions in several pulmonary veins and alongside to the roof and the mitral valve anulus.

Finally, to answer the question about working only on the pulmonary veins alone on both sides, as has been described by some authors, I think that this misses an important connection to the mitral valve. This is why you cannot do the procedure epicardially. The connection to the mitral valve is essential, in our view.

Dr Niv Ad (Tel-Aviv, Israel). I have one question and a quick comment. Looking at your results, especially for the patients in whom the ablation was combined with mitral valve surgery, it is clear that your success rate in abolishing AF is significantly lower than the results reported by Cox and other big series from the United States. What do you think is the reason for this difference? Is it because you are ablating the left side only, or is it because of the use of radiofrequency, which is well known to be an unreliable option for the creation of transmural lesion?

With regard to your presentation of ablation lines in the left atrium, these are basically designed to isolate the pulmonary veins and are based on the experience of the cardiologists, rather then solid research. I think that it may be good enough to some extent for patients with paroxysmal AF, but not for patients with chronic $\mathrm{AF}$ and big atria.

Dr Mohr. I do not believe that this is the final answer to AF in general. I think that the Cox maze procedure is still the criterion standard. I do not think that we can yet answer the question of whether radiofrequency, cryoablation, or microwave is the best energy source. I think we can say, and I think you will agree, that we have to have a continuous transmural lesion. We also work with cryoablation, and the problem is that if you want to do it in a minimally invasive fashion, almost endoscopically, the cryoprobe does not allow you to go everywhere you want to, whereas radiofrequency allows you close contact everywhere, in every corner, and it is faster. Microwave may allow the same thing. I think that we all should look into the possibility of a new energy source that would help us to do it even faster and better. 
The persistent late AF has been looked at by our cardiologists. It has never come from the right side but has always come from the left side. They tried to go back with catheter techniques to close the existing gaps that were present, and I think another reason is the large left atrium. We have to be more aggressive to downsize the atria in such patients. We follow Carpentier's technique to downsize the left atrium. In those cases in which we reduce the volume, we also close the left atrial appendage.
Dr D. Craig Miller (Stanford, Calif). How assured are you that you are getting a full-thickness lesion with these 20-second burns?

Dr Mohr. From the experimental work, we know that with this probe in 20 seconds we penetrate $1 \mathrm{~cm}$, and within 5 seconds we reach, at the epicardium, the temperature of $60^{\circ} \mathrm{C}$. That is why I truly believe that the esophageal lesion may have an impact with this technique. Now that we have isolated it, I hope that we will not see this problem anymore.

\section{Online-www.aats.org}

Now you can get The Journal of Thoracic and Cardiovascular Surgery online. The Journal online brings you faster delivery time, easy searching of current and back issues, links to PubMed, AATS, WTSA, and other important sites, and more. Visit the Journal online today.

\section{Receive tables of contents by e-mail}

To receive the tables of contents by e-mail, sign up through our Web site at http://www.mosby.com/jtcvs

\section{Choose E-mail Notification}

Simply type your e-mail address in the box and click the Subscribe button. Alternatively, you may send an e-mail message to majordomo@mosby.com. Leave the subject line blank and type the following as the body of your message: subscribe jtcvs_toc

You will receive an e-mail to confirm that you have been added to the mailing list.

Note that TOC e-mails will be sent out when a new issue is posted to the Web site. 